\title{
Small Interfering RNA Specific for N-Methyl-D-Aspartate Receptor 2B Offers Neuroprotection to Dopamine Neurons through Activation of MAP Kinase
}

\author{
Olivia T.W. $\mathrm{Ng}^{\mathrm{a}}$ L.W. Chen ${ }^{\mathrm{b}}$ Y.S. Chan ${ }^{\mathrm{c}}$ Ken K.L. Yung ${ }^{\mathrm{a}}$ \\ ${ }^{a}$ Department of Biology, Hong Kong Baptist University, Kowloon Tong, ${ }^{b}$ Institute of Neurosciences, Fourth Military \\ Medical University, Xian, and ' Department of Physiology and Research Center of Heart, Brain, Hormone and \\ Health Aging, University of Hong Kong Kong, Hong Kong, China
}

\section{Key Words}

$\mathrm{N}$-methyl-D-aspartate receptor 2B - Small interference RNA · Parkinson's disease $\cdot$ Motor symptom • Extracellular signal-regulated kinase signaling pathway

\begin{abstract}
In the present study, N-methyl-D-aspartate receptor 2B (NR2B)-specific siRNA was applied in parkinsonian models. Our previous results showed that reduction in expression of $\mathrm{N}$-methyl-D-aspartate receptor 1 (NR1), the key subunit of $\mathrm{N}$ methyl-D-aspartate receptors, by antisense oligos ameliorated the motor symptoms in the 6-hydroxydopamine (6-OHDA)-lesioned rat, an animal model of Parkinson's disease (PD) [Lai et al.: Neurochem Int 2004;45:11-22]. To further the investigation on the efficacy of gene silencing, small interference RNA (siRNA) specific for the NR2B subunit was designed and administered in the striatum of 6-OHDA-lesioned rats. The present results show that administration of NR2Bspecific siRNA decreased the number of apomorphine-induced rotations in the lesioned rats and that there was a significant reduction in NR2B proteins levels after NR2B-specific siRNA administration. Furthermore, attenuation of the loss of dopaminergic neurons was found in both the striatal and substantia nigra regions of the 6-OHDA-lesioned rats that
\end{abstract}

\begin{tabular}{|c|c|}
\hline KARGER & $\begin{array}{ll}\text { (c) 2012 S. Karger AG, Basel } & \text { Karger } \\
1424-862 X / 13 / 0212-0042 \$ 38.00 / 0 & \text { Open access }\end{array}$ \\
\hline $\begin{array}{l}\text { E-Mail karger@karger.ch } \\
\text { www.karger.com/nsg }\end{array}$ & $\begin{array}{l}\text { This is an Open Access article licensed under the terms } \\
\text { of the Creative Commons Attribution-NonCommercial- } \\
\text { NoDerivs } 3.0 \text { License (www.karger.com/OA-license), appli- } \\
\text { cable to the online version of the article only. Distribution } \\
\text { for non-commercial purposes only. }\end{array}$ \\
\hline
\end{tabular}

had been continuously infused with siRNA for 7 days. In addition, a significant upregulation of $p$-p44/42 MAPK (ERK1/2; Thr202/Tyr204) and $p$-CREB (Ser133) in striatal neurons was found. These results suggest that application of the gene silencing targeting NR2B could be a potential treatment of PD, and they also revealed the possibility of NR2B-specific siRNA being involved in the prosurvival pathway.

Copyright $\odot 2012$ S. Karger AG, Basel

\section{Introduction}

Glutamate is the major excitatory neurotransmitter in the basal ganglia [1-3]. Overactivation of the indirect pathway, which includes the glutamatergic transmission from the cortex to the striatum and from the subthalamic nucleus to the output nuclei of the circuit [4-6], is thought contribute to the development of some of the symptoms of Parkinson's disease (PD) [7]. In the striatum, N-methyl-D-aspartic receptors (NMDARs) are ionotropic glutamate receptors which are mostly found to be expressed in the subpopulations of striatal neurons, including striatal projection neurons, i.e. the medium spiny neurons [8-11]. The NMDAR 2B (NR2B) subunit is reported to be the dominant NR2 subunit in the striatum 
$[12,13]$. Previous studies in our laboratory suggested the reduction in expression of NMDAR 1 (NR1), the key subunit of NMDARs, by employing antisense oligonucleotides could ameliorate the motor symptoms in the 6-hydroxydopamine (6-OHDA)-lesioned rat, which is an animal model of PD [14]. Furthermore, Sze et al. [15] showed that a single dose of NR2B-specific antisense oligodeoxynucleotide could successfully block the gene expression of NR2B in neurons of the striatum. Blocking the gene expression of NR2B is therefore found to have potential to generate antiparkinsonian effects.

On the one hand, activation of NMDARs contributes to either neuroprotective [16-19] or neurodestructive [20-23] effects, depending on the subcellular localization of the receptors, as the activation of synaptic NMDARs promotes cell survival signaling pathways, whereas activation of extrasynaptic NMDARs promotes cell death signaling pathways [23]. Moreover, NR2A- and NR2Bcontaining NMDARs are suggested to be expressed in both synaptic and extrasynaptic sites with different ratios $[24,25]$. In the synaptic region, NR2A-containing NMDARs are predominant and can be expressed in either a diheteromeric form with NR1 (NR1/NR2A) or triheteromeric form with NR1 and NR2B (NR1/NR2A/ NR2B) [25-27]. On the other hand, the NR1/NR2B diheteromer NMDARs are predominant in the extrasynaptic region $[24,25,28,29]$. This suggests that NR2A-containing NMDARs contribute to the cell survival signaling pathway while NR1/NR2B-containing NMDARs contribute to the cell death pathway [25]. The mechanisms of the two subpopulations of NMDARs exerting opposite effects are still under investigation. The differences in functions between the synaptic and extrasynaptic NMDARs were related to the different proteins incorporated with the cytoplasmic C-terminal of each NR2 subunit, which leads to the activation of different postsynaptic signaling pathways $[25,30,31]$. One of the well-known signaling pathways interacting with NMDAR is the extracellular signal-regulated kinase 1/2 (ERK1/2) signaling pathway. Activation of the ERK1/2 signaling pathway was reported to cause the phosphorylation of a number of substrates such as transcription factors, signaling molecules and apoptosis-related proteins [32, 33].

In the present study, small interference RNA (siRNA) specific for NR2B were employed as molecular tools for investigating the gene expression and functions of NMDARs in striatal neurons. By comparing it with the traditional antisense oligonucleotide gene knockdown strategy, RNAi-mediated gene silencing was suggested to have a higher efficiency [34].

NR2B siRNA Offers Neuroprotection to Dopamine Neurons
The objectives of the present study were to investigate the effects of NR2B-specific siRNA on the behavioral symptoms and on the striatal and substantia nigra (SN) neurons in the animal model of PD. Moreover, the activities of the signaling pathways and the mechanisms of the neuroprotective effects after application of NR2Bspecific siRNA in an animal model of PD were also investigated. Our experiments focused on the ERK1/2 signaling pathway, the change of the protein levels of phosphorylated-RAF proto-oncogene serine/threonineprotein kinase ( $p$-c-Raf), phosphorylated-MEK ( $p$ MEK1/2), phosphorylated-p44/42 MAPK (also known as extracellular signal-regulated kinases, ERK1/2; pERK1/2; Thr202/Tyr204) and phosphorylated-cAMP response element-binding ( $p$-CREB), which were reported to be the downstream of the activation of the NMDARdependent signaling pathway. We investigated their effect on the animal models continuously infused with NR2B-specific siRNA.

\section{Animals and Methods}

Animals

A total of 153 male Sprague-Dawley rats weighing 200-250 g were used. The animals were obtained from the Laboratory Animal Unit of the University of Hong Kong. The handling of rats and all procedures involving in the use of animals in the experiments were approved in accordance with the Animals (Control of Experiments) Ordinance, Hong Kong Department of Health, Hong Kong, SAR. Great efforts were made to minimize the number of the animals used and reduce the suffering of the animals.

\section{Unilateral Striatal 6-OHDA Lesions}

Rats were deeply anesthetized with sodium pentobarbital (20 $\mathrm{mg} / \mathrm{kg}$ i.p., Nembutal; Abbott Laboratories) immediately before the lesions. The rats were subjected to unilateral stereotaxic injections of 6-OHDA (Sigma) in two striatal sites by using a 10- $\mu$ l Hamilton syringe at the following stereotaxic coordinates; site (1) AP: $+1.4 \mathrm{~mm}, \mathrm{~L}:-2.6 \mathrm{~mm}$, DV: $-5.0 \mathrm{~mm}$; and site (2) AP: $-0.4 \mathrm{~mm}$, L: $-3.8 \mathrm{~mm}$, DV: $-5.0 \mathrm{~mm}$. Six microliters of $3 \mathrm{mg} / \mathrm{ml}$ in $0.9 \%$ saline containing $0.2 \mathrm{mg} / \mathrm{ml}$ ascorbic acid 6-OHDA was injected. The rate of injection was $1 \mu \mathrm{l} / \mathrm{min}$, and the syringe was left in situ for a further $5 \mathrm{~min}$ to prevent back-filling along the injection tract. The animals were allowed to recover after surgery and kept in the animal house of Hong Kong Baptist University.

Behavioral Screening of 6-OHDA-Lesioned Rats

Rat rotation tests were performed in order to determine the success of nigrostriatal denervation after 7 days of lesions by injecting apomorphine $(1 \mathrm{mg} / \mathrm{ml}$ i.p.; Sigma). The number of rotations of each rat in a 30 -min test were recorded. Rats turning more than 13 anticlockwise rotations in 5-min intervals were regarded as successfully lesioned animals. 
Pharmacological Treatment in the Striatal-Lesioned Rats

The nucleotide sequence of NR2B was from the National Center for Biotechnology Information (NCBI) sequence database. The sequences of the siRNA specific for NR2B (antisense: 5'UUGGUACACAU UGCUGUCCAA-3', sense: 5'-GGACAGCAAUGUGUACCAAAA-3'; homologous to 2985-3303 bp of complete coding sequence of Rattus norvegicus NMDAR subtype $2 \mathrm{~B}$ mRNA) was manufactured by Dharmacon.

The pharmacological treatment in the animal models was performed 7 days after lesion surgery. Rats were anesthetized with sodium pentobarbital $(20 \mathrm{mg} / \mathrm{kg}$ i.p., Nembutal; Abbott Laboratories). NR2B-specific siRNA (200 nM) in diethylpyrocarbonatetreated $0.9 \%$ saline was mixed with RNAi vehicle, SilentFect (BioRad). In single injection models, the rats received stereotaxic injections of $7.8 \mathrm{ng}$ siRNA (Dharmacon) into the striatal region using a $10-\mu$ l Hamilton syringe with a blunt 33-gauge needle at the following stereotaxic coordinates, AP: $+0.02 \mathrm{~mm}, \mathrm{~L}:-0.32$ $\mathrm{mm}, \mathrm{DV}:-5.0 \mathrm{~mm}$. The injection was administered at a rate of 0.3 $\mu \mathrm{l} / \mathrm{min}$, and the syringe was left in situ for a further $5 \mathrm{~min}$ to prevent back-filling along the injection tract. Moreover, the same amount of non-sense siRNA (Dharmacon) was also injected into separate animal models as a negative control of the experiment.

In the continuous infusion models, NR2B-specific siRNA (3 $\mathrm{nM}$ ) in diethylpyrocarbonate-treated $0.9 \%$ saline was mixed with RNAi vehicle, SilentFect (Bio-Rad). The osmotic minipumps were filled with $7.8 \mathrm{ng}$ of siRNA for infusion at a rate of $24 \mu \mathrm{l} / \mathrm{day}$ for 1 week (Alzet Model 2001; Durect, Cupertino, Calif., USA). The osmotic minipumps were loaded at room temperature, and these prefilled pumps were placed in isotonic saline overnight at $37^{\circ} \mathrm{C}$ before implantation to ensure a steady pumping rate. A brain-infusion cannula (Brain Infusion Kit 2, Alzet) was stereotaxically placed for infusion from the implanted minipump to the striatal region (AP: $+0.02 \mathrm{~mm}, \mathrm{~L}:-0.32 \mathrm{~mm}, \mathrm{DV}:-5.0 \mathrm{~mm}$ ). The animals were allowed to recover after surgery and kept in the animal house of Hong Kong Baptist University.

\section{Western Blot Analysis}

The protein expression of NR2B, TH, $p$-c-Raf, $p$-MEK1/2, $p$ ERK $1 / 2$ and $p$-CREB in the area of the striatum and the protein expression of TH in the area of SN were studied. An equal amount of protein was loaded onto the sodium dodecyl sulfate-polyacrylamide gel electrophoresis (SDS-PAGE; $5 \%$ for NR2B, $10 \%$ for TH, $p$-c-Raf, $p$-MEK1/2, $p$-ERK1/2 and $p$-CREB) and transferred to a PVDF membrane (Bio-Rad) overnight at $15 \mathrm{~V}$ in transfer buffer (glycine, methanol, Tris-HCL, SDS, pH 8.3). The PVDF membrane was then incubated with blocking agent containing $5 \%$ nonfat powdered milk (Carnation) in TBST-T $(1 \times$ TBS, $0.1 \%$ Tween-20, $\mathrm{pH}$ 7.4) for $1 \mathrm{~h}$ at room temperature. After blocking, the membrane was incubated with anti-NR2B antibody (1:500; Millipore), anti-TH antibody (1:2,000; Millipore), anti- $p$-CREB (1:1,000; Cell Signaling), anti- $p$-ERK1/2 (1:1,000; Cell Signaling), anti- $p$-MEK1/2 (1:1,000; Cell Signaling) or anti- $p$-c-Raf $(1: 1,000$; Cell Signaling), which were diluted in $2 \%$ nonfat powdered milk (Carnation) in TBST-T ( $1 \times$ TBS, $0.1 \%$ Tween-20, pH 7.4) for $2 \mathrm{~h}$ at room temperature. Afterwards, the membrane was incubated with secondary horseradish peroxidase-conjugated secondary antibody (Zymed Laboratories) diluted in 2\% nonfat powdered milk (Carnation) in TBST-T ( $1 \times$ TBS, $0.1 \%$ Tween-20, pH 7.4) for $1 \mathrm{~h}$ at room temperature. The ECL Western blot detection reagents (Amersham Biosciences, England) was used for luminesc- ing the immunoblot for detection, and the resulting light was detected by BioMax film (Kodak). Immunoblots were subsequently stripped using the stripping buffer and sequentially reprobed with the loading control antibody $\beta$-actin (1:3,000, Millipore). The images of the blots after Western blot analysis were digitally scanned by a scanner. The intensity of optical density of each band was semiquantified by an image analyzing software (Metamorph) and statistically by Duncan's multiple range test (SPSS).

\section{Immunohistochemistry}

The rats were deeply anesthetized with an overdose of sodium pentobarbital (60 mg/kg i.p.; Nembutal, Abbott Laboratories) before being perfused transcardially with $300 \mathrm{ml}$ of $0.9 \%$ saline and $300 \mathrm{ml}$ of $3 \%$ of paraformaldehyde (Fluka) with $0.01 \%$ glutaraldehyde (Fluka) in phosphate buffer $(0.1 \mathrm{M}, \mathrm{pH} 7.4)$ with the aid of a peristaltic pump. The brains were removed from the skull quickly after perfusion and post-fixed in $3 \%$ paraformaldehyde (Fluka) overnight at $4^{\circ} \mathrm{C}$. The brains were coronally sectioned at $70 \mu \mathrm{m}$ using a vibrating microtome (Vibratome 1000; Technical Products International Inc.). The sections were collected in phosphatebuffered saline (PBS, $0.01 \mathrm{M}, \mathrm{pH}$ 7.4). The immunoreactivity for $\mathrm{NR} 2 \mathrm{~B}$ or $\mathrm{TH}$ in the striatum and $\mathrm{SN}$ was stained by antibodies from Millipore. The sections were incubated in anti-NR2B (1:500; Millipore) or anti-TH (1:500; Millipore) antibody diluted in PBS $(0.01 \mathrm{M}, \mathrm{pH} 7.4)$ with $0.1 \%$ of Triton X (USB) and $2 \%$ normal goat serum (NBS, Vector Labs). The sections were incubated in the primary antibody solution overnight at room temperature. After incubation, the sections were incubated in fluorochrome-conjugated secondary antibodies (Alexa 488, Molecular Probe) diluted to $1: 500 \mathrm{PBS}(0.01 \mathrm{M}, \mathrm{pH} 7.4)$ against the primary antibodies. The reaction was implemented at room temperature for $2 \mathrm{~h}$ in the dark and stopped by washing three times with $\mathrm{PBS}$ (0.01 M, pH 7.4). After single immunofluorescence, all the sections were mounted on clean slides with mounting medium (DAKO). The sections were observed under a laser scan confocal microscope. Digital images of the areas of interest were captured under the same parameters of the confocal microscope (FluoView ${ }^{\mathrm{TM}}$ FV1000, Olympus) and analyzed with Metamorph software.

\section{Statistical Analysis}

All results were presented as means \pm SD from a minimum of three independent trials. Group data were analyzed by paired $t$ tests, using PASW Statistics 18 software. Significance was set as $\mathrm{p}<0.05$.

\section{Results}

\section{Rotation Number after Single and Continuous Administration of NR2B-Specific siRNA into \\ Lesioned Rats}

A single dose of $200 \mathrm{nM}$ of NR2B-specific siRNA was injected into the striatal region of a 6-OHDA-lesioned rat. To investigate the effects of the NR2B-specific siRNA on the behaviors of the PD models, an apomorphine-induced rotation test was performed on the 7 th day after the lesion surgery and 1 or 2 days after siRNA treatment. The 


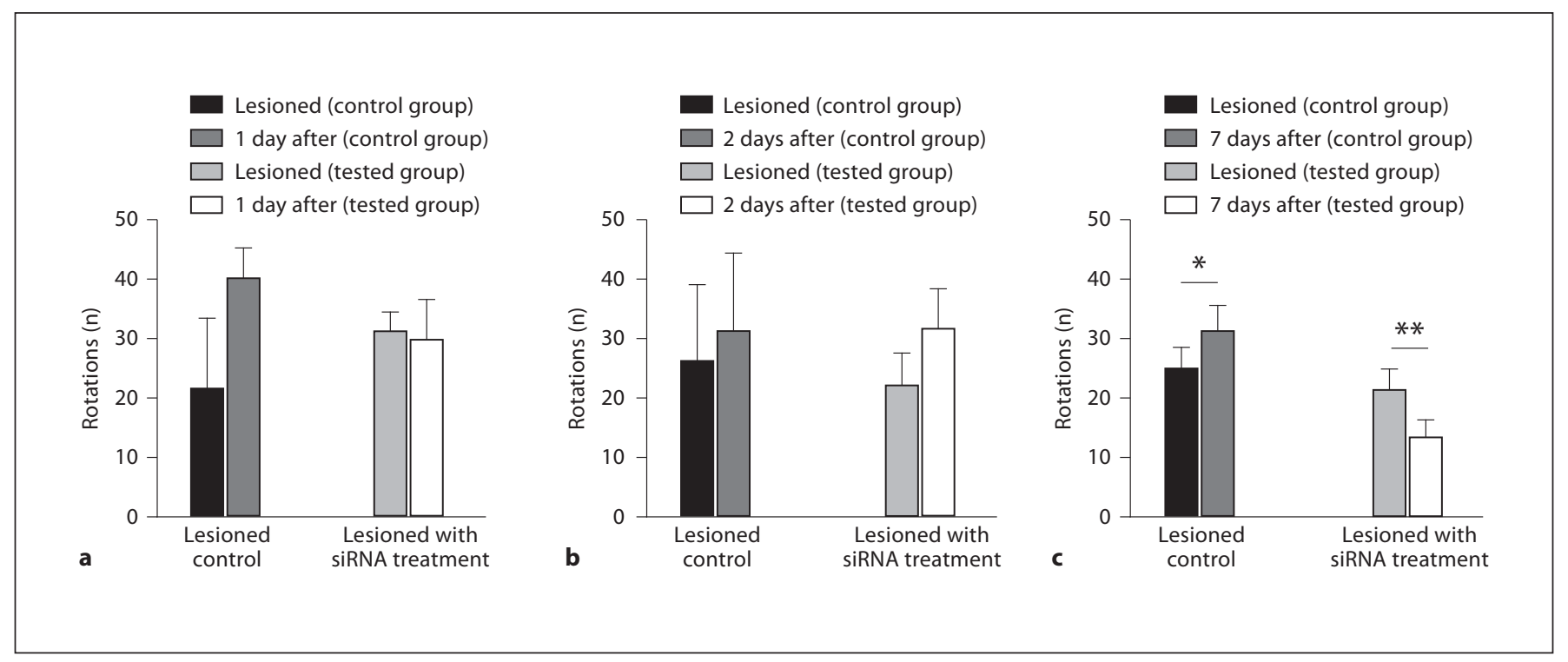

Fig. 1. Rotation number of the 6-OHDA-lesioned parkinsonian models. In each set of experiments, control models were done using lesioned models without any siRNA treatment and recording the rotation number parallel to the tested models. The rotation number before and 1 day (a) or 2 days (b) after the single injection of NR2B-specific siRNA. No significant difference was found. $\mathbf{c}$ The rotation number before and after 7 days of continuous infusion of NR2B-specific siRNA. A significantly different reduction in rotation number was found in the siRNA-treated PD models.

rotation number of the PD models was recorded. The control model was employed by recording the rotation number parallel to the experimental sets without siRNA application. From our experiment, no significant change in rotation number was found in the animal model between the rotation record of before and 1 day after the treatment ( $p>0.05$; fig. 1a) after the statistical analyses. According to the statistical analyses, there was also no significant change in rotation number in the animal model between the record of before and 2 days after the treatment ( $p>0.05$; fig. $1 b)$.

As there was no significant improvement in behavioral effect after applying single injection of NR2B-specific siRNA to the PD models, further investigation on the effects of the siRNA by infusing continuously into the animal models for 7 days was performed; $3 \mathrm{nM}$ of NR2Bspecific siRNA was continuously infused into the striatal region of a 6-OHDA-lesioned rat for 7 days. The total amount of NR2B-specific siRNA infused into the rat models was the same as the single administration. An apomorphine-induced rotation test was performed on the 7th day after the lesion surgery and on the 7th day after the implantation of the siRNA-containing osmotic pump. The control model was employed by recording the

NR2B siRNA Offers Neuroprotection to Dopamine Neurons rotation number parallel to the experimental set without siRNA application. A significant increase in rotation number was found in the lesioned models ( $\mathrm{p}<0.05 ; 19.57$ $\pm 11.69 \%$; fig. 1c). However, a significant reduction of rotation number was found in the siRNA-treated lesioned model. ( $\mathrm{p}<0.001 ; 41.94 \pm 22.13 \%$; fig. $1 \mathrm{c})$.

\section{Protein Expression of NR2B in the Striatum}

In order to ensure the specificity of the NR2B-specific siRNA, the expression of NR2A protein was also examined. The band of NR2A protein (fig. $2 \mathrm{a}$ ) had a molecular weight between 170 and $180 \mathrm{kDa}$. The protein level of NR2A was not found to be reduced in both lesioned models with or without siRNA treatment. Statistical analyses revealed there was no significant reduction $(\mathrm{p}>0.05$; fig. 2b). Furthermore, the silencing effect of NR2B-specific siRNA on the protein expression of NR2B in the models was quantitatively investigated by Western blotting. The expression of NR2B protein was examined in total striatal protein homogenates including both the membrane and cytoplasmic compartments. The band of protein that corresponded to the NR2B protein was observed with molecular weights between 170 and $180 \mathrm{kDa}$. After the single administration of siRNA, a significant 
Fig. 2. Western blot analysis of the protein levels of NR2A in striatal neurons. The protein levels of $\beta$-actin were also analyzed for normalization. The normal (Nor) and lesioned (Les) sides of the same animal model were studied on the same blot. a The immunoreactive band of the protein that corresponded to the NR2A protein which was observed to be about $170-180 \mathrm{kDa}$. b Statistical analyses revealed protein expression of NR2A in the striatum after normalization was not found to be reduced.

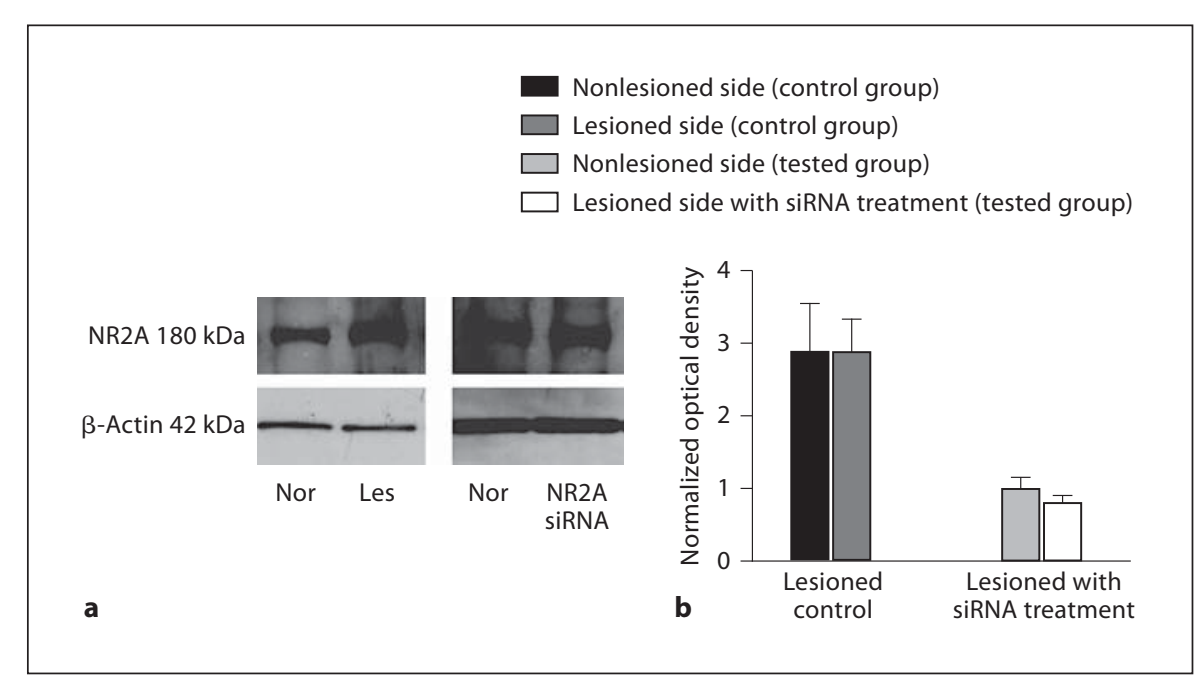

reduction in protein expression of NR2B was found (fig. 3a, b). The protein expression of NR2B was normalized with the expression of $\beta$-actin $(\mathrm{p}<0.05 ; 47.51 \pm$ $15.00 \%$; fig. $3 c$ ). In addition, a non-sense siRNA which was suggested to be minimal targeting of known genes in human, mouse and rat cells (Dharmacon) was used as a negative control in the experiment (fig. 3a, b). In addition, the protein level of NR2B in the PD models was examined after infusing NR2B-specific siRNA for 7 days continuously. The immunoreactive band corresponding to NR2B protein was found to be reduced (fig. 3d). Statistical analyses revealed there was a significant reduction $(\mathrm{p}<0.01$; $57.21 \pm 2.27 \%$; fig. $3 \mathrm{e}$ ).

\section{Protein Expression of TH in the Striatum}

To further investigate the effects of NR2B-specific siRNA on dopaminergic neurons, immunoreactivity for $\mathrm{TH}$ by Western blot analysis was performed. In the present study, the expression of the TH protein was examined in total striatal protein homogenates including the membrane and cytoplasmic compartments. The band of protein that corresponded to the $\mathrm{TH}$ protein was observed with molecular weights of about $60 \mathrm{kDa}$. No observable change in immunoreactivity for TH band was found after 7 days of lesion surgery or after the single administration of siRNA (data not shown). In addition, the protein level of $\mathrm{TH}$ in the PD models was examined after infusing NR2B-specific siRNA for 7 days continuously. The immunoreactive band corresponding to the $\mathrm{TH}$ protein was found to be significantly reduced in the lesioned models 14 days after lesion surgery (fig. $4 \mathrm{a}$ ). Statistical analyses revealed there was significant reduction $(\mathrm{p}<0.01 ; 39.17$ \pm 4.04\%; fig. 4b). After continuous infusion of NR2Bspecific siRNA, no significant reduction of TH immunoreactivity was found. Statistical analyses revealed there was no significant reduction ( $p>0.05)$. This revealed less reduction in $\mathrm{TH}$ protein expression in siRNA-treated $\mathrm{PD}$ models.

The effects of NR2B-specific siRNA on the dopaminergic neurons were investigated by observing the change in immunoreactivity for $\mathrm{TH}$ in the immunofluorescence experiment. The comparison of the immunoreactivity for TH of each model between the nonlesioned side and the NR2B-specific siRNA-treated side of the same adult rat was made. From the results of the confocal microscope, single immunofluorescence showed that the immunoreactivity for $\mathrm{TH}$ in the striatal neurons decreased after lesion surgery $(p<0.05 ; 19.81 \pm 5.39 \%$; fig. $5 a, b)$. On the other hand, there was less reduction of immunoreactivity for $\mathrm{TH}$ after a single injected dose of siRNA ( $p>0.05 ; 2.58 \pm 22.42 \%$; fig. $5 c$, d). The immunofluorescence experiment was performed on the models which underwent continuous infusion of NR2B-specific siRNA for 7 days. Single immunoreactivity revealed that the striatal neurons displayed a decrease in immunoreactivity for $\mathrm{TH}$ after lesion surgery ( $<<0.001 ; 27.63 \pm 6.93 \%$; fig. 5e, f), but no observable change was found in the immunoreactivity for TH after siRNA infusion ( $p>0.05$; $-6.22 \pm 21.0 \%$; fig. $5 \mathrm{~g}, \mathrm{~h}$ ). The decrease in average gray value of the confocal images were measured and shown in the histograms (fig. 5i, j). Statistical analyses revealed there was less reduction in $\mathrm{TH}$ protein expression in siRNA-treated PD models. 


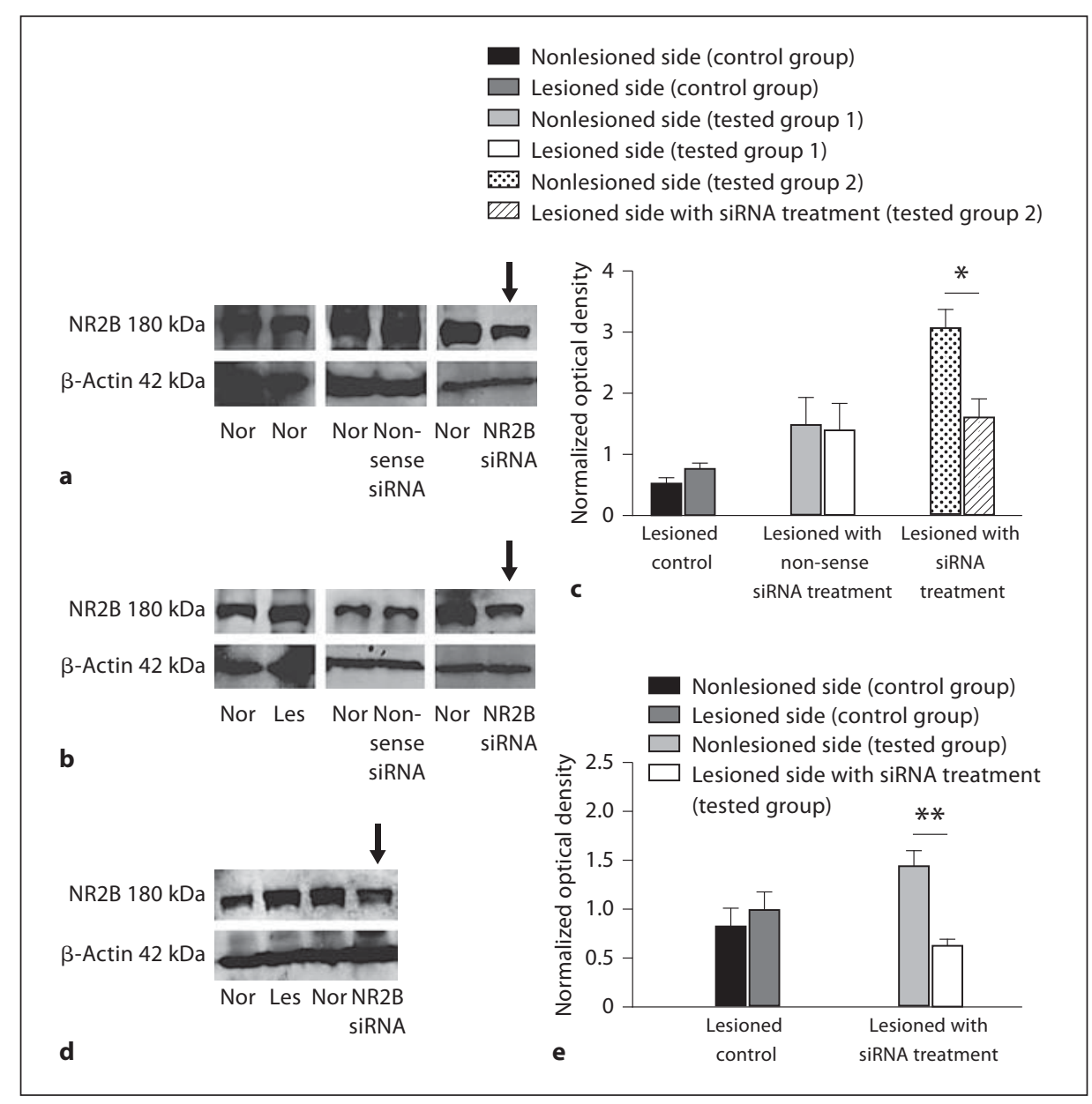

Fig. 3. Western blot analysis of the protein levels of NR2B in striatal neurons. The protein levels of $\beta$-actin were also analyzed for normalization. The normal (Nor) and lesioned (Les) sides of same animal model were studied on the same blot. a Striatum (single injection) of normal rats. A single immunoreactive band of about $180 \mathrm{kDa}$ was observed in each of the samples. Reduction in the protein levels of NR2B were found in the normal models treated with NR2B-specific siRNA. The models treated with non-sense siRNA show no observable change in immunoreactive band of NR2B protein, which acted as a negative control of the experiment. b Striatum (continuous infusion) of 6-OHDA-lesioned rats. A single immunoreactive band of about $180 \mathrm{kDa}$ was observed in each of the samples. Reduction in the protein levels of NR2B were

\section{Protein Expression of TH in the SN}

The expression of $\mathrm{TH}$ protein in the $\mathrm{SN}$ region was revealed by Western blotting. The expression of TH protein was examined in total protein of SN in the homogenates including both the membrane and cytoplasmic compartments. The band of protein that corresponded to TH protein was observed with molecular weights of about 60 found in the lesioned models treated with NR2B-specific siRNA. c Protein expression of NR2B in the striatum after normalization (1 day treatment). Statistical analyses revealed there was a significant reduction in NR2B-specific siRNA-treated lesioned models $(\mathrm{p}<0.05 ; 47.51 \pm 15.00 \%)$. d Striatum (continuous infusion) of 6-OHDA-lesioned rats. A single immunoreactive band of about $180 \mathrm{kDa}$ was observed in the lesioned models. Reduction in the protein levels of NR2B were found in the lesioned models continuously infused with NR2B-specific siRNA for 7 days. e Protein expression of NR2B in the striatum after normalization (1 day treatment). Statistical analyses revealed there was a significant reduction in protein expression of NR2B in the NR2B-specific siRNA-treated lesioned models ( $p<0.01 ; 57.21 \pm 2.27 \%)$.
$\mathrm{kDa}$. The results were similar to that in the striatum, from which the protein expression of $\mathrm{TH}$ was found to have no observable reduction 7 days after lesion surgery or after the single administration of siRNA (data not shown). In addition, the protein level of $\mathrm{TH}$ in the PD models was examined after continuous infusion of NR2B-specific siRNA for 7 days. The immunoreactive 


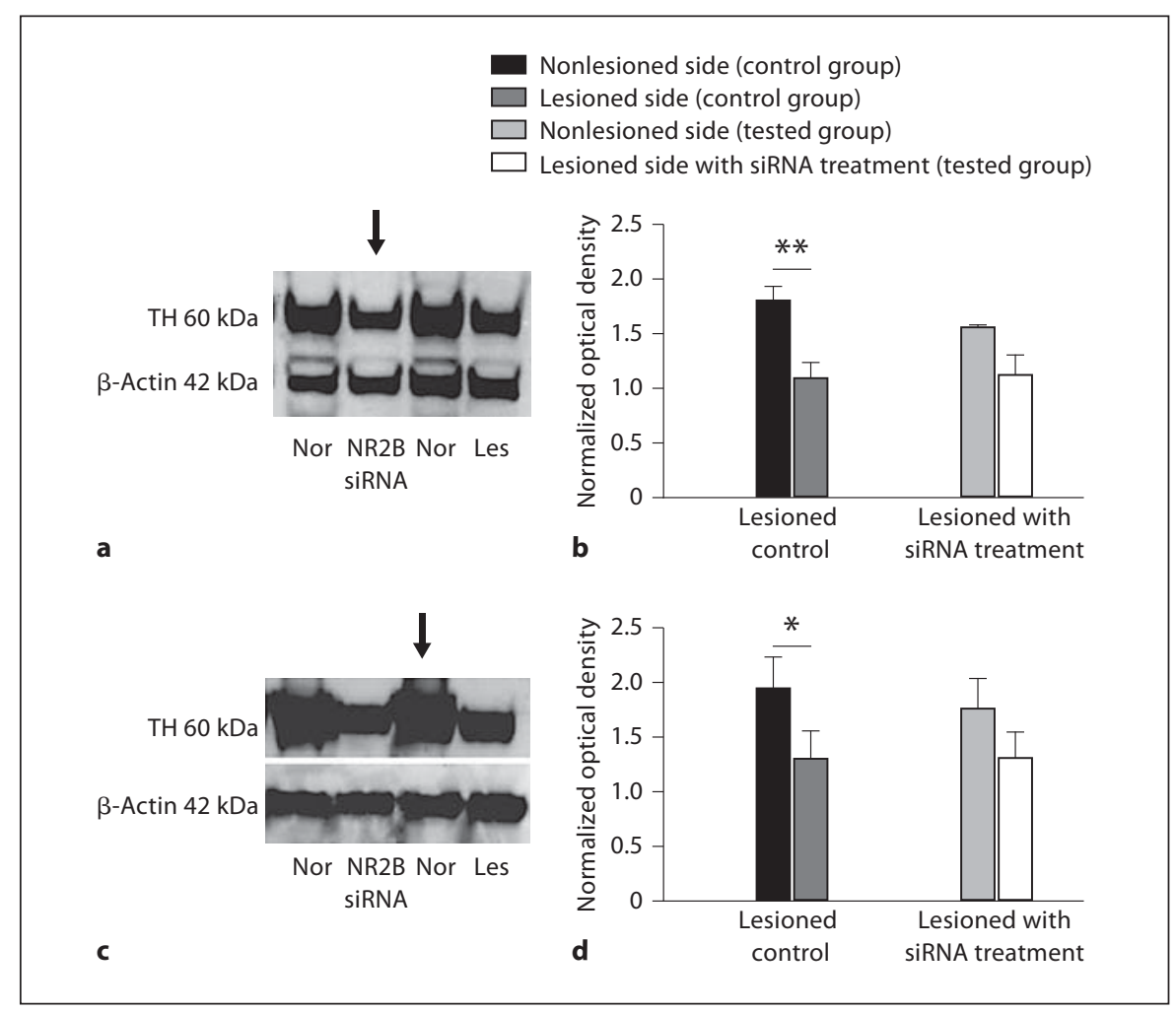

Fig. 4. Western blot analysis of the protein levels of TH in striatal and $\mathrm{SN}$ neurons after continuous infusion of NR2B-specific siRNA. The protein levels of $\beta$-actin were also analyzed for normalization. The normal (Nor) and lesioned (Les) sides of the same animal model were studied on the same blot. a Striatum (continuous infusion) of 6-OHDA-lesioned rats. No observable change in immunoreactivity for the TH band was found in striatal neurons after 7 days of lesion surgery. $\mathbf{b}$ Protein expression of $\mathrm{TH}$ in the striatum of PD models after siRNA treatment (7-day treatment). Statistical analyses revealed there was significant reduction of TH protein expression in striatum of the lesioned models $(\mathrm{p}<0.01 ; 39.17 \pm 4.04 \%)$; however, no significant reduction of $\mathrm{TH}$ protein expression was found in the NR2B-specific siRNA-treated lesioned models. c SN (continuous infusion) of 6-OHDA-lesioned rats. No observable change in immunoreactivity for the TH band was found in SN neurons after 7 days of lesion surgery. d Protein expression of TH in SN of PD models after siRNA treatment (7-day treatment). Statistical analyses revealed there was a significant reduction of $\mathrm{TH}$ protein expression in $\mathrm{SN}$ neurons of the lesioned models ( $\mathrm{p}<0.05 ; 41.91 \pm 5.62 \%$ ); however, no significant reduction of TH protein expression in $\mathrm{SN}$ neurons was found in the NR2B-specific siRNA-treated lesioned models. band corresponding to the $\mathrm{TH}$ protein was found to be significantly reduced in the lesioned models 14 days after lesion surgery (fig. 4c). Statistical analyses revealed there was significant reduction $(\mathrm{p}<0.05 ; 41.91 \pm 5.62 \%$; fig. $4 \mathrm{~d}$ ) in $\mathrm{TH}$ protein expression. However, after infusing NR2B-specific siRNA into the lesioned rat models continuously for 7 days, no significant reduction of TH immunoreactivity was found $(p>0.05)$. Less reduction in $\mathrm{TH}$ protein expression was revealed in siRNA-treated PD models.

Apart from Western blotting, an immunofluorescence experiment was also performed. The comparison of the immunoreactivity for $\mathrm{TH}$ of each model between the nonlesioned side and the NR2B-specific siRNA-treat- ed side of the same adult rat was made. Similar results in the striatum were found. Single immunofluorescence revealed that the immunoreactivity for TH in the SN neurons decreased after lesion surgery (fig. 5k, l). Nevertheless, less reduction of immunoreactivity for $\mathrm{TH}$ after a single dose of siRNA injection was found (fig. $5 \mathrm{~m}, \mathrm{n}$ ). In addition, an immunofluorescence experiment was performed on the models which underwent continuous infusion of NR2B-specific siRNA for 7 days. Single immunoreactivity revealed that the immunoreactivity for $\mathrm{TH}$ in striatal neurons decreased after lesion surgery (fig. 5o, p), but there was no observable change in the immunoreactivity for TH after siRNA infusion (fig. 5q, r). For further investigation on the effects of NR2B-specific siRNA on 


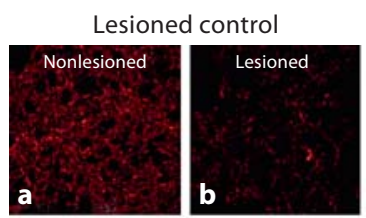

Lesioned treated with siRNA

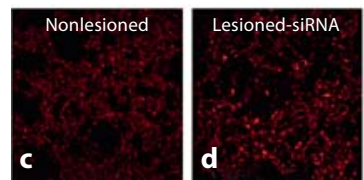

Lesioned control

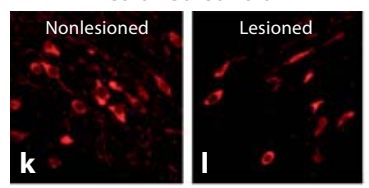

Lesioned treated with siRNA
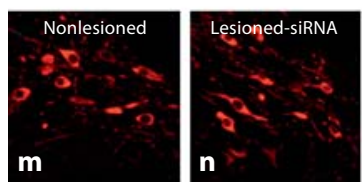

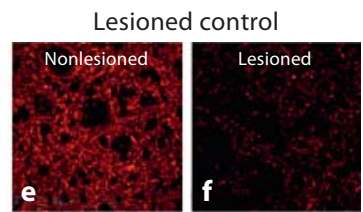

Lesioned treated with siRNA

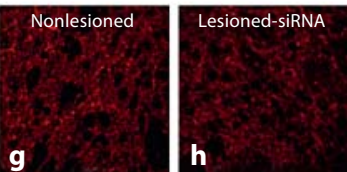

Lesioned control

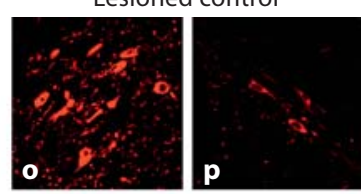

Lesioned treated with siRNA

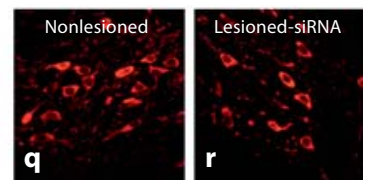

- Nonlesioned side (control group)

$\square$ Lesioned side (control group)

$\square$ Nonlesioned side (tested group)

$\square$ Lesioned side with siRNA treatment (tested group)
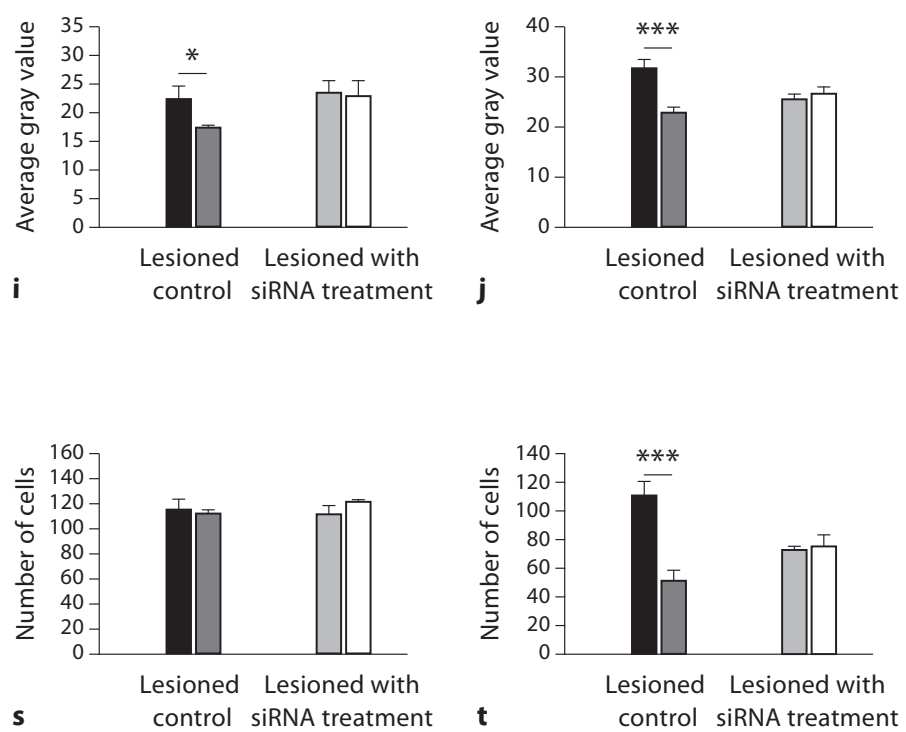

Fig. 5. Immunofluorescence experiment was performed in striatal and SN neurons. a, b Single immunofluorescence revealed that the striatal neurons displayed a decrease in the immunoreactivity for $\mathrm{TH}$ after lesion. c, d Less reduction of immunoreactivity for TH after a single dose of siRNA injection was found. e, f Single immunoreactivity revealed that the striatal neurons displayed a decrease in immunoreactivity for TH after lesion. g, h No observable change in the immunoreactivity for $\mathrm{TH}$ after siRNA infusion. $\mathbf{i}, \mathbf{j}$ Average gray value of the striatum of PD models after siRNA treatment. Statistical analyses revealed there was a significant reduction of $\mathrm{TH}$ protein expression in the striatum of the lesioned models (single injection group; $\mathrm{p}<0.05 ; 19.81 \pm 5.39 \%$; continuous infusion group; $\mathrm{p}<0.001 ; 27.63 \pm 6.93 \%)$. However, no reduction in immunoreactivity for $\mathrm{TH}$ was found in either single administration or continuous infusion of NR2B-specific siRNA-treated PD models. k, I Single immunofluorescence re- vealed that the $\mathrm{SN}$ neurons displayed a decrease in the immunoreactivity for $\mathrm{TH}$ after lesion. $\mathbf{I}, \mathbf{m}$ Less reduction of immunoreactivity for $\mathrm{TH}$ after a single dose of siRNA injection was found. $\mathbf{o}, \mathbf{p}$ Single immunoreactivity revealed that the SN neurons displayed a decrease in immunoreactivity for TH after lesion. q, $\mathbf{r}$ No observable change in the immunoreactivity of TH after siRNA infusion. s, $\mathbf{t}$ Number of TH-positive cells in SN of lesioned models after siRNA treatment. Cell counting was employed and the change in the number of TH-positive neurons after treatment was examined. Statistical analyses revealed there was a significant reduction of TH-positive neurons in SN neurons of the lesioned models (continuous infusion group; $\mathrm{p}<0.001 ; 54.17 \pm 6.12 \%$ ). However, no reduction in the number of TH-positive neurons was found in either single administration or continuous infusion of NR2B-specific siRNA-treated PD models.
SN neurons, cell counting was done in order to examine the change in number of TH-positive neurons. A comparison was made between the nonlesioned side and the lesioned side or lesioned side with siRNA treatment of the same adult rat. The present results show no significant difference in the number of TH-positive neurons in both lesioned-only and siRNA-treated PD models in the single injection group (fig. 5s). However, a significant reduction in number of TH-positive neurons was found in lesionedonly PD models in the continuous infusion group (54.17 $\pm 6.12 \%$; fig. $5 t$ ), while no significant difference was found in the siRNA-treated PD models.

\section{Protein Expression of ERK Signaling Effectors}

Western blot analysis was employed and several effectors in the ERK signaling pathway were investigated in both normal and lesioned animal models, which included $p$-c-Raf, $p$-MEK $p$-ERK1/2 (Thr202/Tyr204) and $p$ CREB. From the results, no observable change in protein level of any investigated effector was found in the normal 
rat models. In the lesioned rat models, no significant difference in the protein expression of $p$-c-Raf was observed after continuous infusion of NR2B-specific siRNA into 6-OHDA lesioned rat models (fig. 6a). $p$-MEK, which is activated by MAP kinase kinase kinase (MAP3K) c-Raf, also showed no significant difference in the protein expression after continuous infusion of NR2B-specific siRNA into 6-OHDA-lesioned rat models (fig. 6b). In addition, the results from Western blot analysis on the striatum of NR2B-specific siRNA-treated 6-OHDA-lesioned rat models revealed a significant increase $(\mathrm{p}<0.05 ; 86.29$ $\pm 62.69 \%$; fig. $6 c$ ) in the protein expression of $p$-ERK1/2 (Thr202/Tyr204). Western blot analysis was also employed on the SN of NR2B-specific siRNA-treated 6OHDA-lesioned rat models. However, the results showed a significant reduction ( $\mathrm{p}<0.05 ; 32.04 \pm 11.80 \%$; fig. $6 \mathrm{e})$ in the protein levels of $p$-ERK1/2 (Thr202/Tyr204) in the siRNA-treated 6-OHDA-lesioned rat models. The change of protein expression of $p$-CREB which could be activated by the ERK signaling pathway was investigated in the present study. The results showed a significant upregulation $(\mathrm{p}<0.05 ; 144.26 \pm 105.63 \%$; fig. $6 \mathrm{~d})$ in the protein expression of $p$-CREB after continuous infusion of NR2B-specific siRNA into 6-OHDA-lesioned rat models. Statistical analyses of different phosphorylated form of effectors in striatal and SN neurons after continuous infusion of NR2B-specific siRNA were done and are showed in a histogram (fig. 7a-e).

\section{Discussion}

The results of the present study indicate that application of NR2B-specific siRNA can potentially conduce the amelioration of motor behavior and reservation of the dopaminergic neurons of PD animal models, especially in the continuous infusion models. Moreover, NR2Bspecific siRNA can promote the survival signaling pathway by upregulating the protein levels of $p$-ERK1/2 and $p$-CREB. These observations may form a basis for applying gene silencing targeting NR2B as a potent treatment of PD.

\section{Change in Rotation Number after Administration of \\ NR2B-Specific siRNA into Lesioned Rats}

The alternations in dopamine receptors in 6-OHDAtreated animal models lead to glutamatergic overstimulation in the indirect striatal output pathway which eventually causes the PD motor symptoms [5, 7]. Moreover, the imbalance in dopamine activity $[35,36]$ will lead the an-

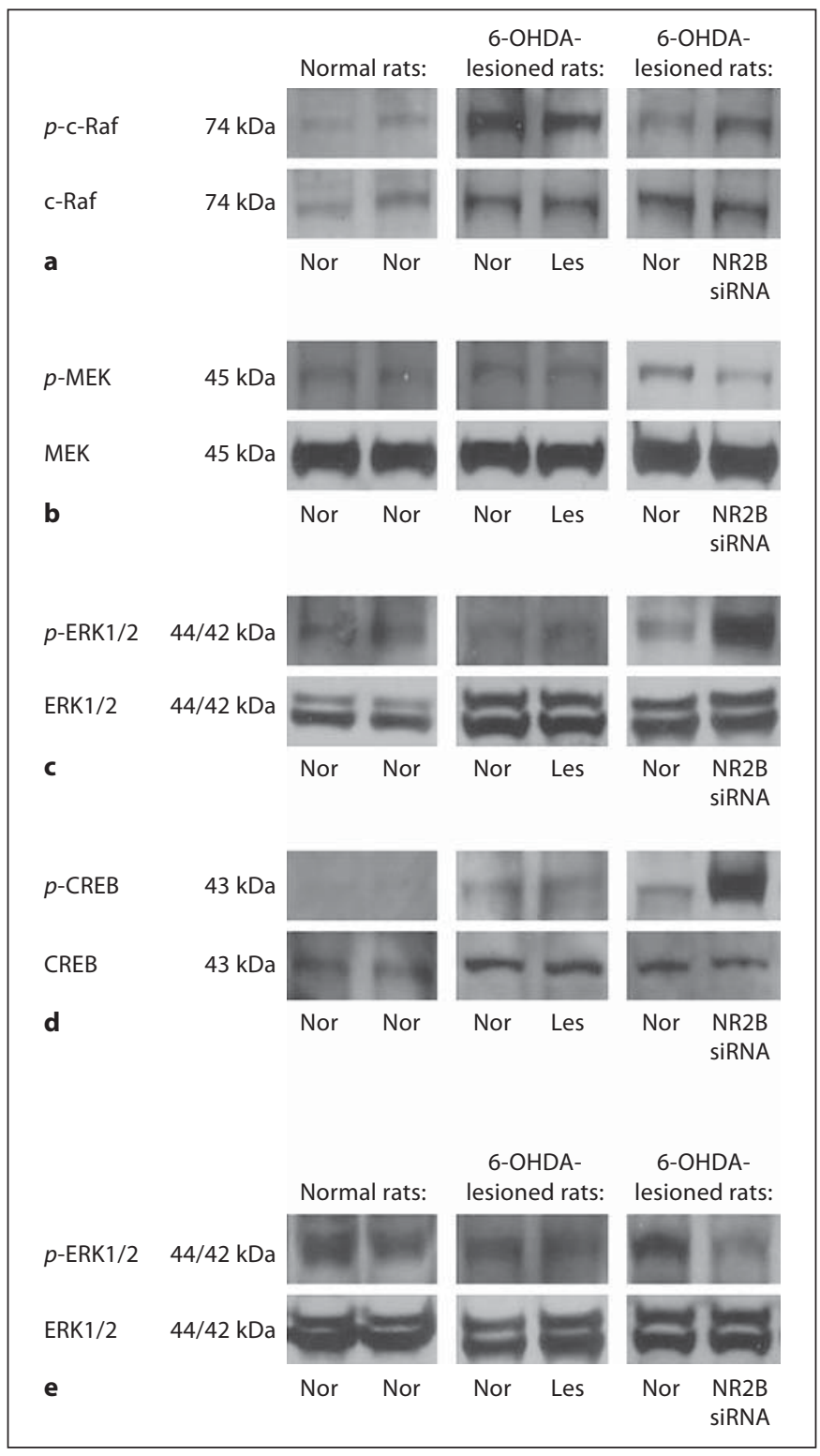

Fig. 6. Western blotting analysis of the protein levels of different phosphorylated forms of effectors in striatal and SN neurons after continuous infusion of NR2B-specific siRNA. The protein levels of the nonphosphorylated form of each effector were also analyzed for normalization. The normal (Nor) and lesioned (Les) sides of the same animal model were studied simultaneously. a No observable change in the immunoreactivity band for $p$-c-Raf was found in striatal neurons. $\mathbf{b}$ No observable change in the immunoreactivity band for $p$-MEK was found in striatal neurons. c A significant upregulation in immunoreactivity band for $p$-ERK1/2 was found in striatal neurons. $\mathbf{d}$ A significant upregulation in the immunoreactivity band for $p$-CREB was found in striatal neurons. e A significant downregulation in the immunoreactivity band for $p$-ERK1/2 was found in SN neurons.
$\mathrm{Ng} /$ Chen/Chan/Yung 


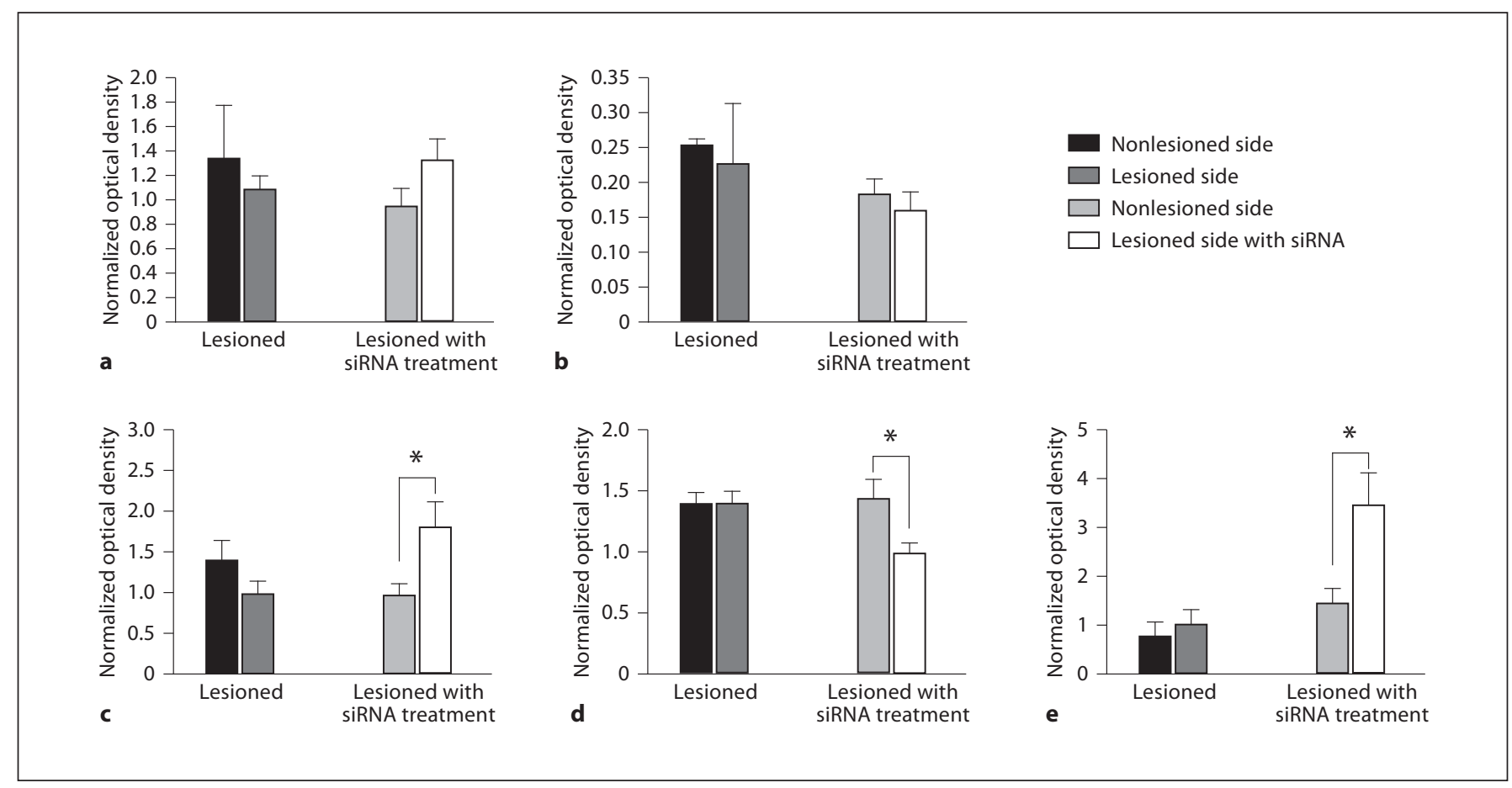

Fig. 7. Statistical analyses of different phosphorylated forms of effectors in striatal and SN neurons after continuous infusion of NR2B-specific siRNA. $p$-c-Raf (a) and $p$-MEK1/2 (b) protein expression in the striatum after normalization. Statistical analyses revealed there was no significant change of $p$-c-Raf and $p$-MEK protein expression in the striatum of NR2B-specific siRNA-treated lesioned models. $\mathbf{c} p$-Erk $1 / 2$ protein expression in the striatum after normalization. Statistical analyses revealed there was significant upregulation of $p$-ERK1/2 protein expression in the striatum of NR2B-specific siRNA-treated lesioned models $(\mathrm{p}<0.05$;
$86.29 \pm 62.69 \%)$. d $p$-Erk $1 / 2$ protein expression in the SN after normalization. Statistical analyses revealed there was significant downregulation of $p$-ERK1/2 protein expression in the $\mathrm{SN}$ of NR2B-specific siRNA-treated lesioned models $(\mathrm{p}<0.05 ; 32.04$ $\pm 11.80 \%)$. e $p$-CREB protein expression in the striatum after normalization. Statistical analyses revealed there was significant upregulation of $p$-CREB protein expression in the striatum of NR2B-specific siRNA-treated lesioned models $(\mathrm{p}<0.05 ; 144.26$ $\pm 105.63 \%)$. imals to respond to dopamine agonists such as apomorphine by contralateral rotation to the lesioned side [3638]. In the present study, the number of rotations between the lesioned models and lesioned-with-siRNA-treatment models were compared. It is shown that a significant modification of motor behavior in the rat rotation test after the treatment of 7 days continuous infusion of NR2B-specific siRNA. As the total administration amount of NR2B-specific siRNA (7.8 ng) used was the same in both the single injection and the continuous infusion models, the differences between the two sets of experiments may be related to the duration of the application of siRNA into the striatal region. After the administration of NR2B-specific siRNA into striatum, expression of functional NMDAR may be reduced. Moreover, the overstimulated glutamatergic activity of striatal neurons may also be reduced, which can further diminish the stimulation on the overactivated subthalamic nucleus and reduce the inhibition on the output nuclei of the basal ganglia and hence reduce the motor symptoms of PD. The present results indicated that the NR2B-specific siR$\mathrm{NA}$ is capable of ameliorating the motor symptoms in parkinsonian models.

\section{Downregulation of NR2B in the Lesioned Side of siRNA-Treated Lesioned Rats}

Overstimulation of NR2B-containing NMDAR in the striatum was reported to contribute to the generation of parkinsonian symptoms [39-42]. The finding in the present study indicated an increasing trend of protein expression of NR2B in the striatum after the lesion surgery, which was in agreement with the previous study [38, 4345]. Furthermore, reduction in NR2B protein expression was found in both the single-dose administration and 
continuous infusion of NR2B-specific siRNA-treated parkinsonian models. By comparing the results between the siRNA treatment by continuous infusion $(\mathrm{p}<0.01$; $57.21 \%$ ) and siRNA treatment by single-dose administration $(\mathrm{p}<0.05 ; 47.51 \%)$, a more significant reduction in NR2B protein expression was found in the striatal region of the infusion models, which indicates continuous infusion is the more efficient application method.

The NMDAR subunits NR2A and NR2B have been reported to be the major subtypes of NMDAR colocalized in the striatum $[7,46]$, and shared considerable homology - up to $70 \%$ identical $[7,47]$. No observable reduction in immunoreactivity for NR2A was found in Western blot analysis, indicating that the siRNA used in the experiment was specific to NR2B mRNA in the striatum. Moreover, a nontargeting siRNA, which was suggested to minimally target known genes in human, mouse and rat cells was purchased from a commercial company (Dharmacon) and acted as a negative control for the experiment. These results also indicated that NR2B-specific siRNA used in the present experiments is an effective agent and specific in blocking the protein expression of the NR2B subunit.

\section{NR2B-Specific siRNA Protect TH-Immunoreactive}

Dopamine Neurons against 6-OHDA Toxicity

Loss of TH immunoreactivity can reveal the loss of the TH-positive neurons, dopaminergic neurons. Previous studies demonstrated that NR2B antagonists exhibited neuroprotective effects $[41,42,48,49]$. In the present study, reduction in $\mathrm{TH}$ immunoreactivity was found in the striatum and SN after 6-OHDA was lesioned. By comparing the TH immunoreactivity of lesioned models and siRNA-lesioned treatment models, a 19.8 or $27.6 \%$ significant decrease in $\mathrm{TH}$ immunoreactivity was found in the PD models 7 or 14 days after lesion surgery, respectively, while only a $5.39 \%$ decrease or $6.21 \%$ increase was found after single or continuous siRNA treatment. These results implicated that dopaminergic cell loss was significantly attenuated and the neuroprotective effect may be mediated by NR2B-specific siRNA. The present results suggest that reduction of the subunit of NMDAR may lead to the decrease of the functional NR2B-containing NMDAR present on the striatum, which may increase the inhibition signal in the indirect pathway. Hence, the overactivation of the glutamatergic activity of the subthalamic nucleus is restored and cell death due to the overstimulation of the NMDAR localized on the dopaminergic neurons is prevented. However, this phenomenon was only observed in the models that underwent continuous infusion of NR2B-specific siRNA. As the total amount of siRNA introduced to the parkinsonian models by the two methods was the same, the effect of siRNA should be related to the duration of the application. In addition, the amount of dopaminergic cell loss was suggested in a previous study, which correlates with behavioral deficit in 6-OHDA-lesioned animal models [42, 50]. In the present study, it can also be concluded that the significant improvement in the behavior in 6-OHDA-lesioned rats with continuous infusion of NR2B-specific treatment may be due to the attenuation of dopaminergic cell loss in the striatum and $\mathrm{SN}$.

\section{Change in $p$-ERK1/2 and Upregulation of $p$-CREB \\ Protein Expression in the Lesioned Side of \\ siRNA-Treated Lesioned Rats}

In the present study, the ERK1/2 prosurvival cascade was hypothesized to be consistent in the neuroprotective phenomenon. The significant upregulation of $p$-ERK1/2 protein after administration of NR2B-specific siRNA revealed that activation of the ERK1/2 signaling pathway occurred. NR2B-containing NMDAR expressed in extrasynaptic NMDAR was reported to trigger a signaling cascade leading to inactivation of the ERK1/2 signaling pathway [26]. Reducing the expression of extrasynaptic NR2B-containing receptors probably results in releasing the inhibition of ERK1/2 activity, i.e. increasing the phosphorylation of ERK1/2. As mentioned earlier, synaptic NMDAR was predominantly composed of NR2A-containing NMDARs [25], which was independent of the silencing effect of NR2B-specific siRNA. Thus, activation of synaptic NR2A-containing NMDARs probably occurs and the influx of $\mathrm{Ca}^{2+}$ may result in triggering the phosphorylation of ERK1/2 which may contribute to the significant increase in $p$-ERK1/2 protein in striatal neurons. Moreover, a significant upregulation of $p$-CREB in NR2B-specific siRNA-treated 6-OHDA-lesioned rats was found in the present study. It is probably related to the activation of the ERK1/2 cascade pathway which was reported to be the exclusively $\mathrm{Ca}^{2+}$-dependent signal transduction pathways that mediated CREB phosphorylation [51]. As CREB is a transcription factor that is well known to be the key element in the neuronal survival pathway [52], Ser133 $p$-CREB carries out prosurvival activities by controlling the transcription of numerous neuroprotective genes [23, 52-54].

However, a significant reduction of $p$-ERK1/2 protein was found in SN neurons. As NR2B-specific siRNA was applied to the striatal region, the neuroprotective effect by reducing the activity of NMDAR NR2B subunits was
$\mathrm{Ng} /$ Chen/Chan/Yung 
less in the $\mathrm{SN}$ region, which is far away from the striatal region. As mentioned before, NR2A-containing and NR1/NR2B receptors mediated opposite effects on neurons, whereby the former exerted a neuroprotective action against apoptotic neuronal injuries while the latter triggered a neuronal death cascade pathway [25]. Therefore, initiation of either neuronal survival or death may depend on the net impact between the activation of the two receptors [25].

In the present study, $p$-c-Raf and $p$-MEK $1 / 2$ were reported to be the upstream effectors of the ERK1/2 signaling cascade, and no significant changes were found in immunoreactivity in siRNA-treated 6-OHDA-lesioned rats. These novel findings reveal the complication of signaling pathways present in vivo. The results show that other MAP3K rather that c-Raf may be involved in the activation of ERK1/2 in the present models. Moreover, the presence of numerous interactions among different kinds of neurons, including dopaminergic neurons, noradrenergic neurons and GABAergic neurons, may result in crosstalk. The present effects of NR2B-specific siRNA on the signaling pathways in parkinsonian conditions remain to be established.

In summary, single injection of siRNA into PD models showed no significant effect in ameliorating the motor syndrome and protection in TH-positive neurons. However, continuous infusion of NR2B-specific siRNA can effectively ameliorate the motor symptoms, attenuate the dopaminergic cell loss in the striatum and SN regions, and promote the ERK1/2 signaling pathway in parkinsonian models. The duration of treatment may be the key factor for the NR2B-specific siRNA to carry out the effect. In the present study, the effect of single injection of siRNA was examined only 1 or 2 days afterwards; the possible effects at a later time window need to be further examined. Nevertheless, introduction of siRNA can employ an effective and specific mRNA knockdown which could prevent side effects. Moreover, by using the osmotic minipump connecting with canals, this method can be easily transplanted into patients, and allow the siRNA to be infused to the target site directly at a steady and slow rate. The direct delivery has the advantages of reducing any undesired systemic side effects and lowering the dose requirement for efficacy [55]. In conclusion, continuous infusion of siRNA is possible to be developed into a new therapy for ameliorating the motor syndrome of PD.

\section{Acknowledgements}

The present project was supported by Hong Kong Baptist University Research Committee Mini-Area of Excellence Scheme (RC/AOE/08-09/02) and General Research Fund, Hong Kong Research Grants Council (HKBU 262107 and HKBU 262210). The present work was also partially supported by the Area of Excellence Scheme established under the University Grants Committee of the HKSAR (Project No. AoE/B-15/01). The authors would like to thank Mr. W.K. Ip, Miss L.H. Ng and Mr. W.S. Chung of Hong Kong Baptist University for technical assistance.

\section{References}

1 Gerfen CR, Wilson CJ: The basal ganglia; in Swanson LW, Bjoklund A, Hökfelt T (eds): Handbook of Chenical Neuroanatomy: Integrated system of the CNS, Part 3. Amsterdam, Elsevier, 1996, vol 12, pp 371-486.

-2 Smith Y, Bevan MD, Shink E, Bolam JP: Microcircuitry of the direct and indirect pathways of the basal ganglia. Neuroscience 1998;86:353-387.

-3 Tepper JM, Abercrombie ED, Bolam JP: Basal ganglia macrocircuits. Prog Brain Res 2007; 160:3-7.

4 Alexander GE, DeLong MR, Strick PL: Parallel organization of functionally segregated circuits linking basal ganglia and cortex. Annu Rev Neurosci 1986;9:357-381.

-5 Blandini F, Mappi G, Tassorelli C, Martignoni E: Functional changes of the basal ganglia circuitry in Parkinson's disease. Prog Neurobiol 2000;62:63-88.
6 DeLong MR, Wichmann T: Circuits and circuit disorders of the basal ganglia. Arch Neurol 2007;64:20-24.

7 Loftis JM, Janowsky A: The $N$-methyl- $D$-aspartic receptor subunit NR2B: localization, functional properties, regulation, and clinical implications. Pharmacol Ther 2003;97: 55-85.

8 Chen Q, Veenman CL, Reiner A: Cellular expression of ionotropic glutamate receptor subunits on specific striatal neuron types and its implication for striatal vulnerability in glutamate receptor-mediated excitotoxicity. Neuroscience 1996;73:715-731.

-9 Bernard V, Bolam JP: 1998. Subcellular and subsynaptic distribution of the NR1 subunit of the NMDA receptor in the neostriatum and globus pallidus of the rat: colocalization at synapses with the GluR2/3 subunit of the AMPA receptor. Eur J Neurosci 1996;10: 3721-3738.
10 Chen Q, Veenman L, Knopp K, Yan Z, Medina L, Song WJ, Surmeier DJ, Reiner A: Evidence for the preferential localization of glutamate receptor-1 subunits of AMPA receptors to the dendritic spines of medium spiny neurons in rat striatum. Neurosci $1998 ; 83$. 749-761.

11 Avshalumov MV, Patel JC, Rice ME: AMPA receptor-dependent $\mathrm{H}_{2} \mathrm{O}_{2}$ generation in striatal medium spiny neurons but not dopamine axons: one source of a retrograde signal that can inhibit dopamine release. J Neurophysiol 2008; 100:1590-1601.

12 Standaert DG, Friberg IK, Landwehrmeyer GB, Young AB, Penney JB: Expression of NMDA glutamate receptor subunit mRNAs in neurochemically identified projection and interneurons in the striatum of the rat. Brain Res Mol Brain Res 1999;64:11-23. 
13 Lynch DR, Guttmann RP: Excitotoxicity: perspertives based on $N$-methyl- $D$-aspartic receptor subtypes. J Pharmacol Exp Ther 2002;300:717-723.

14 Lai SK, Ng TKY, Lau WK, Yang MS, Wong CKC, Chan YS, Yung KKL: Selective knockdown of gene expression of N-methyl-D-aspartate receptor one ameliorates parkinsonian motor symptom in 6-hydroxydopamine-lesioned rats. Neurochem Int 2004;45: 11-22.

15 Sze SCW, Wong CKC, Yung KKL: Modulation of the gene expression of $N$-methyl- $D$ aspartic receptor NR2B subunit in the rat neostriatum by a single dose of specific antisense oligodeoxynucleotide. Neurochem 2001;39:319-327.

16 Hardingham GE, Bading H: The yin and yang of NMDA receptor signaling. Trends Neurosci 2003;26:81-89.

$\checkmark 17$ Lee B, Butcher GQ, Hoyt KR, Impey S, Obrie$\tan \mathrm{K}$ : Activity-dependent neuroprotection and cAMP response element-binding protein (CREB): kinase coupling, stimulus intensity, and temporal regulation of CREB phosphorylation at serine 133. J Neurosci 2005;25:1137-1148.

- 18 Papadis S, Stevenson P, Hardingham NR, Bading $\mathrm{H}$, Hardingham GE: Nuclear $\mathrm{Ca}^{2+}$ and cAMP response element-binding protein family mediate a late phase of activitydependent neuroprotection. J Neurosci 2005;25:4279-4287.

-19 Soriano FX, Papadia S, Hofmann F, Haedingham NR, Bading $\mathrm{H}$, Haedingham GE: Preconditioning doses of NMDA promote neuroprotection by enhancing neuronal excitability. J Neurosci 2006;26:4509-4518.

20 Choi DW: Excitotoxic cell death. J Neurobiol 1992;23:1261-1276.

21 Lipton SA: Paradigm shift in neuroprotection by NMDA receptor blockage: memantine and beyond. Nat Rev Drug Discov 2006 5:160-170.

22 Kalia LV, Kalia SK, Sliter MW: NMDA receptors in clinical neurology: excitatory times ahead. Lancet Neurol 2008;7:742-755.

-23 Hardingham GE: Coupling of the NMDA receptor to neuroprotective and neurodestructive events. Biochem Soc Trans 2009;37: 1147-1160.

24 Tovar KR, Westbrook GL: The incorporation of NMDA receptors with a distinct subunit composition at nascent hippocampal synapses in vitro. J Neurosci 1999;19:41804188.

-25 Liu Y, Wong TP, Aarts M, Rooyakkers A, Lui L, Lai TW, Wu, DC, Lu J, Tymianski M, Craig AM, Wang YT: NMDA receptor subunits have differential roles in mediating excitotoxic neuronal death both in vitro and in vivo. J Neurosci 2007;27:2846-2857.

-26 Ivanov A, Pellegrino C, Rama S, Dumalska I, Salyha Y, Ben-Ari Y, Medina I: Opposing role of synaptic and extrasynaptic NMDA receptors in regulation of the extracellular signalregulated kinases (ERK) activity in cultured rat hippocampal neurons. J Physiol 2006; 572:789-798

27 Thomas CG, Miller AJ, Westbrook GL: Synaptic and extrasynaptic NMDA receptor NR2 subunits in cultured hippocampal neurons. J Neuroohysiol 2006;95:1727-1734.

28 Stocca G, Vicini S: Increased contribution of NR2A subunits to synaptic NMDA receptors in developing rat cortical neurons. J Physiol Lond 1998;507:13-24.

29 Tovar KR, Westbrook GL: Mobile NMDA receptors at hippocampal synapses. Neuron 2002;34:255-264.

30 Sheng M, Pak DT: Ligand-gated ion channel interactions with cytoskeletal and signaling proteins. Annu Rev Physiol 2000;6:755-778.

- 31 Kohr G, Jensen V, Koester HJ, Mihaljevic AL, Utvik JK, Kvello A, Ottersen OP, Seeburg $\mathrm{PH}$, Sprengei R, Hvalby O: Intracellular domains of NMDA receptor subtypes are determinants for long-term potentiation induction. J Neurosci 2003;23:10791-10799.

$32 \mathrm{Lu}$ Z, Xu S: ERK1/2 MAP kinases in cell survival and apoptosis. IUBMB Life 2006;58: 621-631.

33 Yoon S, Seger R: The extracellular signalregulated kinase: multiple substrates regulate diverse cellular functions. Growth Factors 2006;24:21-44.

34 Kurreck J: siRNA efficiency: structure of sequence - that is the question. J. Biomed. Biochem 2006:2006:83757.

-35 Ungerstedy U: Postsynaptic supersensitivity after 6-hydrox-dopamine induced degeneration of the nigro-striatal dopamine system. Acta Physiol Scand Suppl 1971;367:69-93.

36 Deumens R, Blokland A, Prickaerts J: Modeling Parkinson's disease in rats: an evaluation of 6-OHDA lesions of the nigrostriatal pathway. Exp Neurol 2001;175:303-317.

37 Ungerstedy U: 6-hydroxy-dopamine induced degeneration of central monoamine neurons. Eur J Pharmacol 1986;5:107-110.

-38 Dunah AW, Wang Y, Yasuda RP, Kameyama K, Huganir RL, Wolfe BB, Standaert DG: Alterations in subunit expression, composition, and phosphorylation of striatal $\mathrm{N}$ methyl- $D$-aspartic glutamate receptors in a rat 6-hydroxydopamine model of Parkinson's disease. Mol Pharmacol 2000;57:342352.

39 Loopuijt LD, Schmidt WJ: The role of NMDA receptors in the slow neuronal degeneration of Parkinson's disease. Amino Acids 1998; 14:17-23.

-40 Palmer GC: Neuroprotection by NMDA receptor antagonists in a variety of neuropathologies. Curr Drug Targets 2001;2:241271.

41 Nash JE, Brotchie JM: Characterisation of striatal NMDA receptors involved in the generation of parkinsonian symptoms: intrastriatal microinjection studies in the 6-OHDA-lesioned rat. Movement Disorders 2002;17:455-466.

42 Leaver KR, Allbutt HN, Creber NJ, Kassiou M, Henderson JM: Neuroprotective effects of a selective B-methyl-D-aspartate NR2B receptor antagonist in the 6-hydroxydopamine rat model of Parkinson's disease. Clin Exp Pharmacol Physiol 2008;35:1388-1394.

43 Menegoz M, Lau LF, Hervé D, Huganir RL, Girault JA: Tyrosine phosphorylation of NMDA receptor in ray striatum: effects of 6-OH-dopamine lesions. Neuroreport 1996; 7:125-128.

44 Oh JD, Russel D, Vaughan CL, Chase TN: Enhanced tyrosine phosphorylation of striatal NMDA receptor subunits: effect of dopaminergic denervation and L-DOPA administration. Brain Res 1998;813:150-159.

45 Lai SK, Tse YC, Yang MS, Wong CK, Chan YS, Yung KK: Gene expression of glutamate receptors GluR1 and NR1 is differentially modulated in striatial neuron in rats after 6-hydroxydopamine lesion. Neurochem Int 2003;43:639-653.

46 Fritschy JM, Weinmann O, Wenzel A, Benke D: Synapse-specific localization of NMDA and $\mathrm{GABA}_{\mathrm{A}}$ receptor subunits revealed by antigen-retrieval immunohistochemistry. J Comp Neurol 1998;390:194-210.

47 Monyer H, Sprengel R, Schoepfer R, Herb A, Higuchi M, Lomeli H, Burnashev N, Sakmann B, Seeburg PH: Heteromeric NMDA receptors: molecular and functional distinction of subtypes. Science 1992;256:12171221.

48 Tzschentke TM: Glutamatergic mechanisms in different disease states: overview and therapeutical implications. An introduction. Amino Acid 2002;23:147-152.

49 Hallett PJ, Standaert DG: Rationale for and use of NMDA receptor antagonists in Parkinson's disease. Pharmacol Ther 2004;102: 155-174.

-50 Truong L, Allbutt H, Kassiou M, Henderson JM: Developing a preclinical model of Parkinson's disease: a study of behavior in rats with graded 6-OHDA lesion. Behav Brain Res 2006;169:1-9.

51 Zanassi P, Paolillo M, Feliciello A, Avvedimento EV, Gallo V, Schinelli S: cAMP-dependent protein kinase induces cAMP-response element-binding protein phosphorylation via an intracellular calcium release/ ERK-dependent pathway in striatal neurons. J Biochem 2001;276:11487-11495.

52 Chalovich EM, Zhu J, Caltagarone J, Bowser $\mathrm{R}$, Chu CT: Function repression of cAMP response element in 6-hydroxydopaminetreated neuronal cells. J Biol Chem 2006;281: 17870-17881.

53 Finkbeiner S: CREB couples neurotrophin signals to survival messages. Neuron 2000; 25:11-14.

54 Walton MR, Dragunow M: Is CREB a key to neuronal survival. Tresnd Neurosci 2000;23: 48-53.

55 de Fougerolles A, Vornlocher HP, Maraganore J, Lieberman J: Interfering with disease: a progress report on siRNA-based therapeutics. Nature Rev 2007;6:443-453. 